\title{
Os feminismos e seus sujeitos ${ }^{6}$
}

\author{
Feminisms' subjects
}

\section{Carla Rodrigues}

Docente do programa de pós-graduação de filosofia da UFRJ

\section{Ana Emília Lobato}

Doutoranda do programa de pós-graduação de filosofia da UFRJ

Resumo: O presente artigo pretende retomar o debate travado na década de 1990 das feministas americanas Seyla Benhabib, Judith Butler, Nancy Fraser e Drucilla Cornell acerca das possibilidades e limitações da aliança entre feminismo, pós-estruturalismo e teoria crítica a fim de pensar a questão do sujeito no atual contexto de racionalidade neoliberal.

Palavras-chave: sujeito, feminismo, pós-estruturalismo, teoria crítica.

Abstract: this article intends resume a debate that took place in the 90' among the american feminists Seyla Benhabib, Judith Butler, Nancy Fraser and Drucilla Cornell about the possibilities and limitations of the alliance between feminism, poststructuralism and critical the-

$6 \quad$ Este artigo faz parte da pesquisa "Judith Butler: do gênero à violência de estado", projeto Jovem Cientista do Nosso Estado, Faperj, 2018/2020 
ory, in order to think about the question of the subject in the current neoliberal political scenario.

Keywords: subject, feminism, poststructuralism, critical theory.

\section{Introdução}

A motivação inicial desse artigo é a retomada de um tema Acaro à filosofia: o sujeito, categoria moderna que passa pelo século XX sendo descentrado, abalado, reinscrito, reescrito, clivado, mas cuja razão, desejo e lugar ainda constituem o eixo do debate político contemporâneo. Se, como argumenta Gérard Wajcman ${ }^{7}$, o século XX é o dos objetos, e o objeto que melhor representa o século XX é a ruína, a compreensão do sujeito como parte das ruínas do século passado inspiraram nossa intenção de retornar ao sujeito a fim de recuperar um debate muito específico, travado nos anos 1990 entre pensadoras feministas nos EUA. A recente tradução brasileira de "Debates feministas - um intercâmbio filosófico" - livro em que Seyla Benhabib, Judith Butler, Nancy Fraser e Drucilla Cornell divergem sobre limites e possibilidades de aliança entre feminismo, pós-estruturalismo e teoria crítica - nos servirá de pretexto para voltar à questão do sujeito como ponto central da política contemporânea, seus limites, suas tensões e possibilidades. Embora o livro apresente um debate ocorrido no início dos anos 1990, encontramos atualidade numa das principais conclusões de Nancy Fraser, qual seja, a de que o feminismo se beneficiaria de uma aliança entre pós-estruturalismo e teoria crítica. Concordando com ela, gostaríamos de retomar a esse ponto específico da divergência entre Butler e Benhabib, a questão do sujeito, não apenas a fim de reafirmar a importância da aliança proposta por Fraser, mas de localizá-la no atual e necessário enfrentamento da racionalidade neoliberal e suas consequências, como veremos na última parte.

$7 \quad$ "A ruína é um objeto bem formado, conforme à compreensão comum que se tem do objeto, que ocupa um lugar no espaço, pode ser produzido, ser acessível aos sentidos, ainda que, na prática, este se apresente como ligeiramente desestruturado" (Wajcman, 2012, p. 57) 
Os "debates feministas" que compõe o volume foram promovidos em um simpósio organizado pelo Greater Philadelphia Philosophy Consortium. Corriam os anos 1990 e o então chamado "pós-modernismo" - denominação vaga e imprecisa que estamos reproduzindo apenas porque aparece no ensaio de Seyla Benhabib - acenava o encerramento de horizontes que se desenhava com o chamado fim da história. Tratava-se do que Benhabib chama de "luta contra as grandes narrativas do Iluminismo ocidental e da modernidade" (BENHABIB, 2018, p.35), retomando, não sem um grau de ironia, os termos com que Jean-François Lyotard havia definido a condição pós-moderna (LYOTARD, 2000). Hoje, é mais ou menos fácil de perceber que, diante do fim do horizonte de expectativas, havia um novo tempo do mundo em que olhar para trás parecia ser a chance de rever e, por que não, refazer certos percursos que haviam consolidado um conjunto de formas de opressão a serem desmontadas.

O fim das grandes narrativas apontaria, seguindo muito de perto o argumento de Benhabib, para a morte do homem, da história e da metafísica. Por uma economia interna do texto, vamos nos concentrar em mostrar como essa crítica aparece na Gramatologia, um dos textos fundamentais do chamado pós-estruturalismo francês, para em seguida analisar a hipótese de alianças feministas e, por fim, concluir apontando a atualidade da proposição de Nancy Fraser.

\section{Gramatologia e os três fins}

Publicado em 1967, mesmo ano em que a Voz e o Fenômeno e Escritura e Diferença, as três obras reúnem textos do filósofo Jacques Derrida acerca de temas diversos (alguns já editados em revistas especializadas, outros inéditos), mas que em seu conjunto esboçam algumas ideias fortes do pós-estruturalismo ou o que na França ficará conhecido como pensamento da desconstrução. Em uma entrevista a Henri Ronse, Derrida concorda que, talvez, os três livros pudessem ser lidos como se fossem um sistema aberto. Diz talvez porque constantemente os textos se remetem uns aos outros, mas sobretudo porque este 
remetimento performatiza já um dos argumentos do autor: $o$ fim do livro como uma unidade considerada na sua perfeita totalidade (DERRIDA, 2001, p.09-10).

De fato, aquilo que o pensamento da desconstrução se esforça em criticar é uma certa noção de totalidade, ligada a um desejo de presença plena, que teria presidido a história da filosofia, desde seu começo. É a partir dessa premissa que o filósofo vai propor um deslocamento do conceito de linguagem e uma reflexão sobre a história da escrita no ocidente. Ele começa fazendo um diagnóstico da crise do conceito de linguagem. Como, "por um movimento lento cuja Necessidade mal se deixa perceber," a escrita parece ultrapassar a extensão daquilo que se compreendia por linguagem. "Tudo acontece como se o conceito ocidental de linguagem se revelasse hoje como a forma ou a deformação de uma escrita primeira: mais fundamental do que a que antes desta conversão, passava como 'mero suplemento da fala"' (DERRIDA, 2013, p.09). Esta definição da escrita - mero suplemento da fala - proposta por Rousseau e retomada por Derrida algumas vezes ao longo de Gramatologia, serve como motivo para questionar esta tradição cujo fundamento era a voz.

A fala viva fora sempre celebrada ao longo da história da filosofia, enquanto a escrita foi tomada por monstruosidade, deformação e ameaça. Isso porque a voz ao sair da interioridade daquele que fala não cai completamente na exterioridade e mais que isso, atesta a presença e a propriedade de um discurso, de um logos. Já a escrita era posterior, ferramenta de "fixação" que conduziria a fala viva à morte, tornando distante a presença, sendo o significante de um significante mais originário. E "originário" aqui se deve ao fato de que o pensamento se faria linguagem primeira e naturalmente pela voz, a palavra falada. Sendo assim, o logocentrismo, enquanto metafísica da presença, rebaixou a escrita condenando-a à exterioridade do sentido significado. Ela era um acidente na linguagem e sua função, secundária e instrumental - um suplemento perigoso.

Mais ainda, a substância fônica que constitui a voz deve ao seu caráter não-mundano o privilégio de ser substância de expressão constitutiva da idealidade e da universalidade. A voz 
ouve-se, e, ouvindo-se, faz a experiência do apagamento do significante nela mesma. Ela apaga-se como marca, como rastro, porque ouve-se no mais próximo de si, não solicita nada de fora de si mesma, não precisa de nenhuma outra substância de expressão que não ela mesma em sua própria espontaneidade. E é como se o significado se produzisse nesta experiência da espontaneidade interior da voz - "auto-afeção pura que tem necessariamente a forma do tempo" (DERRIDA, 2013, p.24). Esse apagamento, esse logro, essa dissimulação da voz que já não se mostra como significante, mas como substância de expressão transparente do pensamento (do conceito, do significado, do sentido do ser) é a história da metafísica - que se confunde com a aventura do logocentrismo e se produz inteiramente como redução do rastro (DERRIDA, 2013, p.122).

A época do logos corresponde ainda a época do signo, a aparente evidência tranquilizadora da unidade da diferença significado/significante. Estes jamais são contemporâneos, há entre eles - necessariamente - uma defasagem, talvez o tempo de um sopro. Esta é a condição do signo: que o significado não seja constituído em seu sentido por sua relação com um possível rastro. Enquanto o significante é radicalmente dependente do significado, sendo dele o rastro, isto é, o indício que remeteria a qualquer coisa que já estivera presente, a essência formal do significado é a presença mesma; de fato, é este o privilégio de sua proximidade com o logos. A noção de signo somente pode ser pensada a partir da presença, sua "essência formal" depende disto. Essa noção de signo pertence completamente à época do logos. (DERRIDA, 2013, p.22).

Rastro e escrita são dois termos que no texto de Derrida funcionam quase como conceitos, mais tarde serão chamados indecidíveis. Uma vez que está em operação a desconstrução do regime de linguagem regulado pelo signo, significante de significante - escrita, portanto - parece descrever o movimento de significação, o significado funcionando aí desde sempre como um significante. A linguagem como a escrita, torna-se jogo de diferimento e diferenciação, de significante a significante. Não há havendo signo, há entretanto rastro. 
A estratégia derridiana de leitura do signo, um duplo movimento de inversão e deslocamento deste par (significado/ significante) que o compõe, não visa salvar a escrita de seu rebaixamento, mas antes deslocar o que servia de eixo na linguagem. Pretende afirmar a escrita como não presença mesmo, e ainda assim como uma espécie de estrutura - desestruturante - do jogo do mundo. (DERRIDA, 2013, p.61). Uma tal escrita, portanto, não pode mais estar restrita à escrita fonética, "será necessário pensar que a escrita é o jogo na linguagem", e que este, pensado como ausência de um significado plenamente presente em si, não cabe mais no conceito de jogo regulado pela presença, tal qual o definiu a metafísica a fim de o conter. A linguagem pensada por Derrida como escrita diz respeito menos a uma estrutura que a um movimento do rastro. Em seu sentido comum, rastro é um vestígio deixado por um ente-presente que se fez ausente, um significante que remeteria a uma presença modificada em ausência. Mas, uma vez que o limite que separava significado/significante foi deslocado, o rastro precisaria ser pensado como a escrita, para além desta oposição. De modo que rastro será aquilo a partir do qual um vir-a-ser do signo é possível e com ele todas as oposições ulteriores (natureza/cultura, transcendente/imanente, verdade/ não-verdade, sujeito/objeto, etc) - "o rastro não é nada, não é um ente, excede a questão o que é e eventualmente a possibilita" (DERRIDA, 2013, p.92).

Neste ponto, gostaríamos de retomar o argumento Benhabib e tentar delinear em que medida uma meditação sobre a escrita, ou uma gramatologia corresponderia a morte da metafísica, da história e do homem. Já de início, uma gramatologia somente poderia se desenvolver sob a condição de um abalo profundo desta época histórico-metafísica na qual linguagem se reduziria a dimensão do signo. É preciso lembrar que o privilégio da voz sobre a escrita, Derrida bem o evidencia, foi uma necessidade:

"o sistema do 'ouvir-se-falar' através da substancia fônica teve de dominar durante toda uma época a história do mundo, até mesmo produziu a ideia de mundo, a ideia de origem do mundo a partir da diferença entre mundano e não mundano, o fora e o dentro, idealidade e a não-idealidade, o universal e o não-universal, o transcendental e o empírico, etc." (DERRIDA, 2013, p. 09). 
Por isso, pensar linguagem como escrita se trataria menos de ultrapassar este sistema a fim de estabelecer um novo, mas antes de uma tentativa refletir sobre aquilo que a noção de totalidade almejada pela metafísica não alcança, aquilo que sempre resta, o que não se deixa conquistar.

É deste modo que "o fim do livro e começo da escrita", título do primeiro capítulo de Gramatologia, não faz referência a sucessão de uma época por outra, mas a um limiar desde sempre aí e que a metafísica ao longo de sua história procurou conjurar através do rebaixamento da escrita, tomada como escrita linear. Limiar como uma espécie de princípio (como origem e regra) a que Derrida também chama rastro. A época do signo se constitui numa história em cuja temporalidade tem a forma de uma linha - Heidegger chamou este modelo de tempo "vulgar". Esta é uma temporalidade comprometida com a presença, na qual o passado e o futuro são formas modificadas de presente (um presente que passou, um presente que ainda não chegou). A linguagem do signo supunha um certo modelo de tempo, a linha: "o conceito linearista de tempo é uma das mais profundas aderências do conceito moderno de signo a sua história." (DERRIDA, 2013, p.89). E Heidegger já havia mostrado como este conceito "vulgar" de tempo determina a partir do interior toda ontologia do ser como presença. (DERRIDA, 2013, p.107).

O tempo pensado neste modelo permite supor uma origem pura (ou um telos) para a história e toda a organização do mundo e da linguagem são solidárias a esta noção. O presente é aquilo que nunca está, mas que organiza toda a vida na época histórico metafísica do logos.

A temática da historicidade, embora pareça introduzir-se bem tarde na filosofia, sempre foi nela requerida pela determinação do ser como presença. (...) o conceito de episteme sempre chamou o de história se a história é sempre a unidade de um devir, como tradição da verdade ou desenvolvimento da ciência orientado para a apropriação da verdade na presença e a presença em si, para o saber na consciência de si. A história foi sempre pensada como o movimento de uma ressunção da história, derivação entre duas presenças. (DERRIDA, 2009, p.423-4) 
Uma outra condição para uma gramatologia seria, portanto, a desconstrução da história. A escrita sendo totalmente histórica não se deixa apreender neste modelo, antes, ela é a abertura e possibilidade do devir histórico do qual depende a história.

Por fim, uma gramatologia "não deve ser uma das ciências do homem, porque coloca de início, como sua questão própria o nome do homem" (DERRIDA, 2013, p.104). Pois que este nome - homem - também se constitui nesta época histórico-metafísica e corresponde a um certo regime de visibilidade dos objetos. Aquele que fala (o sujeito) cria uma espécie de espaço virtual do qual ele mesmo seria o fundamento e no qual os objetos podem ser dispostos. É como se seu discurso instituísse a objetividade dos objetos ao submetê-los a este regime de presença. Pensar uma linguagem deslocada, que já não pode ser decifrada pela unidade do signo, é pois, colocar em questão aquele que acredita poder operar esta linguagem, é também descolocar o sujeito (SAFATLE, 2014, p.10).

\section{Quem vem após o sujeito?}

$\mathrm{O}$ artigo de Benhabib, "Feminismo e pós-modernismo: uma aliança complicada", apresenta uma série de objeções acerca do que ela chama de "morte do sujeito", todas bastante compatíveis com um conjunto de contestações - à esquerda ou à direita - então em voga no que podemos chamar de "apelo de retorno ao sujeito". ${ }^{8}$ O tema levou Jean-Luc Nancy a organizar, em 1988, um conjunto de conversas movidas pela pergunta "Quem vem depois do sujeito?", respondida por uma série de autores e publicadas primeiro na França e depois nos EUA 9 . Em

\footnotetext{
$8 \quad$ A este respeito, gostaríamos de referir a DUQUE-ESTRADA, 2005 e ainda ao livro Penser le sujet aujoud'hui (Guibert-Sledziewski\&Vieillard-Baron, 1988), resultado de um colóquio realizado em Cerisy-la-Salle, em 1986, onde o debate sobre o sujeito foi movido pela ideia de reconstrução do conceito de sujeito.

$9 \quad$ Alain Badiou, Didier Franck, Emmanuel Levinas, Etienne Balibar, Gerard Granel, Gilles Deleuze, Jacques Derrida, Jacques Rancière, Jean-François Courtine, Jean-François Lyotard, Jean-Luc Marion, Luce Irigaray, Maurice Blanchot, Michel Henry, Mikkel BorchJacobsen, Philippe Lacoue-Labarthe, Sarah Kofman, Sylviane Agacinski, Vincent Descombes. As respostas foram
} 
sua resposta, Derrida rejeita com veemência o que considera ser a premissa da formulação, a de que o sujeito está morto:

\begin{abstract}
Se ao longo dos últimos 25 anos, na França, as mais notórias dessas estratégias procederam, com efeito, a uma espécie de explicação acerca da "questão do sujeito", nenhuma delas procurou "liquidar" o que quer que seja (aliás, não sei a qual conceito filosófico pode corresponder esta palavra, que compreendo melhor em outros códigos: finanças, banditismo, terrorismo, criminalidade civil ou política; e, portanto, não se fala de "liquidação" senão na posição da lei e mesmo da polícia). O diagnóstico de "liquidação" denuncia em geral uma ilusão e uma falta, ele acusa: quis-se "liquidar", acreditou-se poder fazê-lo, não deixaremos que o façam. O diagnóstico implica, pois, uma promessa: faremos justiça, salvaremos ou reabilitaremos o sujeito. Palavra de ordem, portanto: retorno ao sujeito, retorno do sujeito (DERRIDA, 2018, p.152).
\end{abstract}

Se trazemos aqui a resposta de Derrida é menos para nos debruçar sobre seus argumentos e mais para aproximá-los de alguns dos termos da resposta de Judith Butler às contestações de Benhabib, cuja recusa à aliança entre pós-modernismo e feminismo passa primeiro pela afirmação de que, com a morte do sujeito, "desaparecem conceitos de intencionalidade, responsabilidade, autorreflexão e autonomia", um dos argumentos que leva Benhabib a concluir que a morte do sujeito não seria compatível com objetivos feministas de emancipação, agência, autonomia e individualidade (BENHABIB, 2018, p. 41). Observamos que a recusa ao modo de compreensão do sujeito no pós-estruturalismo produz dois movimentos no artigo de Benhabib: o primeiro, explícito, de recusar o pós-estruturalismo como aliado ao feminismo; o segundo, implícito, o de afirmar que os objetivos do feminismo são emancipação, agência, autonomia e individualidade. É difícil, de fato, discordar que estes sejam objetivos de uma parcela do feminismo, mas também é difícil concordar que haja estabilidade ou homogeneidade no modo como diferentes teorias e movimentos feministas entendem esses valores, em suas diversidades regionais, culturais, sociais e étnicas. Bastaria pensar, por exemplo, no quanto esses valores modernos estão carregados de etnocentrismo e nos im-

reunidas na França no volume 20 do Cahiers Confrontation, em 1989, e traduzidas numa edição nos EUA organizada por Eduardo Cadava, Peter Connor e Jean-Luc Nancy (1991). 
pedem de pensar que talvez não sejam os mais decisivos para mulheres que vivem em comunidades periféricas, nas quais ideias como autonomia e individualidade, por exemplo, podem ser atomizadoras e carregadas do peso de uma responsabilidade individual, incompatível com a vida coletiva.

(A questão nos levaria para uma breve digressão a respeito da compreensão do conceito de colonialidade do poder, de Anibal Quijano (2014), e de seu desdobramamento em colonialidade de gênero, em Maria Lugones (2008), para pensar que no feminismo decolonial o sujeito é generificado e racializado a fim de produzir a relação de exploração capitalista que eliminará as formas sociais comunitárias e de solidariedade que estavam sustentadas em outros modos de divisão do trabalho.)

Acreditamos que, apesar de sua ligação com o pensamento pós-estruturalista, é também muito em função da argumentação de Behabib que Butler se vê diante da exigência de responder pela aliança entre feminismo e pós-modernismo em termos que, de fato, já não representavam exatamente a sua posição dentro da teoria feminista. Grande parte das críticas de Benhabib a ela dirigidas tomam como ponto central uma das questões políticas mais instigantes de Gender trouble, livro que havia sido publicado em 1990, mesmo ano da realização do simpósio: e se a mulher deixasse de ser o sujeito do feminismo?

Olhar retrospectivamente para a perturbação de gênero causada por Butler nos permite, antes de avançar na exposição de sua linha argumentativa, recuperar alguns dos seus desdobramentos. Gender Trouble é uma reunião de textos escritos nos anos que antecedem a queda do Muro de Berlim e que estão sob influência do já mencionado fim das grandes narrativas, mas também dos discursos finalistas que emergiram a partir daí: o fim da história carregaria com ele também o fim do movimento feminista, no rastro da percepção de que as mulheres já teriam conquistado toda a emancipação, agência, autonomia e individualidade que poderiam reivindicar. Butler estava se opondo a esse diagnóstico quando dirige sua provocação para os movimentos feministas, o que gostaríamos de considerar um "verdadeiro momento filosófico", retomando a 
definição que Patrice Magnilier (2011) havia dado à Gramatologia. Isso porque desde então, teóricas feministas de diferentes espectros de pensamento e de localizações geográficas distintas precisam retornar a essa questão, repetindo o gesto que Magnilier encontrou no livro de Derrida. ${ }^{10}$ Sabemos que, no momento seguinte à publicação de Gender Trouble, Butler se dedica a uma trilogia de títulos que buscaram responder muitas das críticas feitas ao livro, sobretudo ao tema da performatividade de gênero (BUTLER; 1993; 1997a; 1997b). No entanto, acreditamos também que o gesto de desconstrução do sujeito do feminismo marcou e ainda marca o debate nas teorias e nas lutas feministas.

\section{Sujeitos interseccionais, sujeitos sexuais}

Um aspecto relevante dos problemas de gênero foi o que hoje, retrospectivamente, podemos considerar uma adesão de Butler à interseccionalidade, questão recém-posta à mesa pela feminista negra Kimberlé W. Crenshaw (1989), que vai ganhando força e expansão à medida em que interpela o feminismo liberal branco a repensar a centralidade da categoria mulher, cujos cruzamentos com raça e classe e condição colonial estavam sendo gestados pelo menos desde os anos 1980, com os trabalhos de Angela Davis (1981), nos EUA e Lélia Gonzalez (1988; 2017), no Brasil. São em grande medida as feministas negras as que forçam a percepção de que não bastava a criação de um sujeito universal feminino, já que este também reproduzia internamente a hierarquia existente na categoria do sujeito universal abstrato, ignorando, alijando e mesmo forcluíndo as mulheres negras. Butler percebe e endereça essa questão aos feminismos, quando escreve:

(...) em Beauvoir, o "sujeito", na analítica existencial da misoginia, é sempre já masculino, fundido com o universal, diferenciando-se de um "Outro" feminino que está fora das normas universalizantes que constituem a condição de pessoa, inexoravelmente "particular",

10 "Um momento filosófico não seria simplesmente uma época, que se poderia definir por um certo número de teses ou pressupostos; é sempre a abertura de um pensamento que reivindica incessantemente ser reprisado, e só pode ser reprisado ao ser renovado" (MAGNILIER, 2011, p. 372). 
corporificado e condenado à imanência. Embora veja-se frequentemente em Beauvoir uma defensora do direito de as mulheres se tornarem de fato sujeitos existenciais, e portanto, de serem incluídas nos termos de uma universalidade abstrata, sua posição também implica uma crítica fundamental à própria descorporificação do sujeito epistemológico masculino abstrato (BUTLER, 2003, p.31).

A condenação das mulheres a serem sujeitos corporificados e imanentes é ainda mais acentuada na condição da mulher negra. Por isso, consideramos que um dos movimentos importantes de Butler é em direção do feminismo interseccional e de sua ampliação, não apenas na necessária discussão sobre raça, mas também na inclusão da sexualidade como marcador interseccional. Para isso, primeiro ela precisará desestabilizar a mulher - até ali entendida como a mulher, branca, heterossexual, europeia - como sujeito do feminismo:

(...) é um problema político que o feminismo concorde que a admissão do termo "mulheres" denota uma identidade em comum. Em vez de um significado estável que comanda a concordância das pessoas a que o termo propõe descrever e representar, mulheres, mesmo no plural, se tornou um termo problemático, um lugar de contestação, um motivo de ansiedade. Como sugere o título do livro de Denise Riley, "Am I that name?" [Eu sou esse nome?], esta é uma questão produzida pelas inúmeras possibilidades desse nome e de suas múltiplas significações. Se alguém "é" uma mulher, certamente isso não é tudo que a pessoa é; o termo fracassa ao tentar ser exaustivo, não porque a pré-generificação de uma "pessoa" transcende a parafernália específica do seu gênero, mas porque gênero não é sempre constituído de forma coerente e consistente em contextos históricos diferentes, e porque gênero faz intersecção com com modalidades raciais, classistas, étnicas, sexuais e regionais de identidades discursivamente constituídas. Resulta que se tornou impossível separar a noção de "gênero" das interseções políticas e culturais em que invariavelmente ela é produzida e mantida (BUTLER, 1990, p.3, itálicos nossos). ${ }^{11}$

A instabilidade apontada como motor para pensar a interseccionalidade será retomada por Butler no ensaio que apresenta na interlocução que estabelece com Benhabib. Sob o título "Fundações contingentes: feminismo e a questão do pós-modernismo", Butler faz um movimento que consideramos muito próximo à mencionada abordagem de Derrida para o problema do sujeito, quando argumenta que exigir uma noção

\footnotetext{
11 Sempre que a referência for a um livro original, a tradução é nossa.
} 
de sujeito que não esteja pressuposta não é dispensar a noção de sujeito, mas interrogar qual é o processo de sua construção e, mais, quais são as consequências políticas de aceitar o sujeito como um pressuposto, sem complexificar suas configurações, contornos e limites (BUTLER, 2018a, p. 63). "Os fundamentos funcionam como o inquestionado e o inquestionável dentro de qualquer teoria", escreve Butler, no que poderíamos chamar de um modo derridiano de abordar as questões ali discutidas, inclusive o problema do sujeito como fundamento implícito ou mesmo oculto e, por isso mesmo, aquilo que precisa seguir não interrogado para que a teoria permaneça funcionando. $\mathrm{Na}$ complexa teia que forma o sujeito, que deixa de estar pressuposto na teoria para estar ali implicado, situado, assujeitado ou localizado, se quisermos falar como Donna Haraway.

Nunca é demais lembrarmos que, desde sua tese de doutorado, e reiteradamente a seguir, a filósofa mantém uma estreita relação com as questões hegelianas: "Todo o meu trabalho está inscrito em torno de um conjunto de perguntas hegelianas: 'qual é a relação entre desejo e reconhecimento e a que se deve que a constituição do sujeito suponha uma relação radical e constitutiva com a alteridade?", escreve (BUTLER, 1999, p. xiv). Vinte anos depois, em entrevista recente, ela tempera essa posição:

Digamos que Hegel continua presente projetando uma sombra sobre o meu trabalho, se bem que, se tomado isoladamente, ele não constitui um parâmetro suficiente para o que faço atualmente. (...) Suponho que compartilho do pressuposto de que aquilo que somos como enquanto sujeitos depende fundamentalmente das relações sociais que nos formam e daquelas nas quais estamos engajados (...) não acredito que os termos do reconhecimento estejam separados dos campos da política e da economia. As duas esferas se condicionam mutuamente (BUTLER, 2019, p.18).

Observamos que é com Foucault que Butler faz o entrelaçamento entre reconhecimento e as condições de possibilidade de ser reconhecido, de modo que a concepção foucaultiana de assujeitamento - aqui entendido como a ambiguidade de um sujeito que se faz sujeito conforme se sujeita às normas do poder - permanece como questão no seu pensamento. Ainda 
que, como ela diz nessa mesma entrevista, ao comentar a publicação brasileira de "Debates feministas", tenha se afastado do pós-estruturalismo e se aproximado da teoria crítica, gostaríamos de sustentar que o problema do sujeito permanece como herança, se não do pós-estruturalismo como um todo, mas em uma certa operação de desconstrução dos pressupostos de autonomia, individualidade, liberdade e agência, para repetir os valores elencados por Benhabib, aos quais outros feminismos foram acrescentando reconhecimento, interdependência, redes de sustentação e sentido de comunidade.

Aqui, seria importante considerar a hipótese de que o movimento de aproximação de Butler com o pós-estruturalismo francês dos anos 1960/1970 se mantém ligado a uma economia de pensamento, a um modo - estamos evitando propositalmente a palavra método - de fazer filosofia que, se por um lado terá a indelével marca hegeliana da dialética, por outro lado, sustentará também uma forma de crítica social que volta o olhar para aquilo que pretendia permanecer oculto como fundamento dos sistemas filosóficos. Não foi outro seu movimento ao apontar que o conceito de gênero havia permanecido como fundamento implícito de um determinismo cultural e substituído o sexo como fundamento da diferença sexual. ${ }^{12}$ Essa pos-

$12 \quad$ Está em funcionamento, em Butler, uma economia de pensamento em relação ao par sexo/gênero que pode ser entendida como análoga ao movimento de leitura que Derrida faz do par significante/significado na linguística estruturalista de F. Saussure. Não se trataria, em nenhum dos dois casos, de uma superação dos sistemas sobre os quais ambos se debruçam, mas principalmente da aguda percepção daquilo que restou impensado. Esse movimento marca a abordagem pós-estruturalista, na medida em que propõe olhar para os sistemas de pensamento a partir de suas lacunas. A este respeito, aproximamos duas citações: "Aparentemente, a teoria de Beauvoir trazia consequências radicais, que ela própria não antecipou", escreve Butler (1990, p.112); "Há ao menos um momento no qual Saussure renuncia a extrair todas as consequências do trabalho crítico que empreendeu" (DERRIDA, 2001, p. 25). Para mais sobre a relação entre Problemas de gênero e Gramatologia, referimos a Rodrigues (2008; 2009). Esse movimento da teoria feminista pode ser localizado ainda na relação que Lugones estabelece com a obra de Quijano: "Quero ressaltar a conexão que existe entre o trabalho das feministas que estou citando aqui ao apresentar o lado obscuro/oculto do sistema de gênero moderno/colonial e o trabalho de Quijano sobre a colonialidade do poder" (LUGONES, 2008, p. 99). 
sibilidade de ampliar a visão permitiu, primeiro em Relatar a si mesmo (BUTLER, 2015a), mas sobretudo em Quadros de guerra (BUTLER, 2015b), que Butler tenha se dedicado a articular as condições de possibilidade de reconhecimento com o tema da moldura, se valendo tanto da teoria do enquadramento, do sociólogo E. Goffman, quanto da abordagem derridiana para o problema da moldura como aquilo que não pode estar fora do quadro e que, ao ser compreendida como um elemento que participa do quadro, borra distinções dadas como garantidas. Ver a moldura passa a ser, portanto, perceber duas possibilidades: modificar o quadro, todo quadro é modificável.

\section{Alianças contingentes}

Aqui, retomamos nossa referência aos "Debates feministas", passando ao texto de Nancy Fraser, "Falsas antíteses: uma resposta a Seyla Benhabib e Judith Butler". Seu artigo funciona como uma espécie de moderação entre as posições de Benhabib e de Butler, retomando seus próprios argumentos a favor de uma teoria feminista que "preservaria a força emancipatória social-crítica mesmo quando evitasse fundamentos filosóficos" (BUTLER, 2018a, p.98) Disso resultariam feminismos que pudessem superar, acredita Fraser, e nós a seguimos muito de perto, "a falsa antítese entre teoria crítica e pós-estruturalismo". Para ela, se faltava ao texto de Benhabib a oportunidade de aceitar tal superação, também faltava a Butler "integrar considerações crítico-teóricas em sua moldura foucaultiana pós-estruturalista." (BUTLER, 2018a, p. 109). Ainda que Fraser aceite - com ressalvas - a proposição de Butler sobre a impossibilidade de estabilizar o termo "mulheres", o argumento forte de seu ensaio está na defesa de uma concepção de subjetividade que seja ao mesmo tempo construída e crítica, propondo uma aliança que, passados 30 anos da discussão ali estabelecida, se provou necessária:

Poderíamos tentar desenvolver novos paradigmas de teoria feminista que integrem as observações da teoria crítica com o pós-estruturalismo. Tais paradigmas engendrariam importantes ganhos intelectuais e políticos e descartariam de vez as falsas antíteses dos nossos debates atuais. (FRASER, 2018, p. 115). 
O debate entre Butler e Fraser continuou ao longo da década de 1990. Há uma edição brasileira da troca de artigos entre as duas na New Left Review, em 1997, com tradução de Alexia Bretas e publicação na revista Ideias (BUTLER, 2017 [1997]). Havia uma tensão produtiva na discussão sobre formas de enfrentamento do capitalismo que não fossem "meramente culturais", na expressão crítica de Fraser, e incorporasse marcadores interseccionais além do já clássico tripé gênero/raça/classe, considerando, nas proposições de Butler, o quanto sujeitos marcados por não corresponder aos padrões heteronormativos experimentam formas de exclusão que se manifestam na vida social e econômica. Estaria aqui, também, o deslocamento de um feminismo feito em função do conceito de gênero e da diferença sexual binária para um feminismo cuja questão central se torna a crítica à heteronormatividade, como propõe Butler.

Quase duas décadas depois, na mesma New Left Review, Fraser publica "Feminism, capitalism and the cunning of history" (FRASER, 2009). O ano era 2009 e a derrocada financeira já havia varrido os mercados internacionais a partir dos Estados Unidos, marcando o que alguns autores vão chamar de "crise do neoliberalismo". ${ }^{13}$ Nosso argumento é que será no enfrentamento das novas configurações do sujeito na racionalidade neoliberal que tem se dado a superação do que Fraser chamou de "falsas antíteses" a fim de impulsionar as alianças contingentes, nos feminismos, mas não apenas, entre teoria crítica e pós-estruturalismo, a primeira compreendendo a necessidade de pensar como os modos de subjetividade participam das formas de opressão; a segunda admitindo que era indispensável considerar a agudização das condições materiais nas novas configurações do capitalismo, agora já capaz de adotar para si transformações culturais e reivindicações das políticas identitárias, amortecendo, portanto, seus modos de opressão sob a fachada da diversidade cultural. O desejo, que era um elemento desestabilizador, por que a ele não corresponde um objeto que se estabilize nessa relação, o desejo será o próximo território a ser conquistado e ocupado.

13 A denominação "crise do neoliberalismo" encontramos, por exemplo, em Duménil e Lévy (2014). 
Da vasta bibliografia sobre as configurações do sujeito neoliberal, vamos privilegiar "A nova razão do mundo", de Pierre Dardot e Christian Laval, no ponto específico em que eles descrevem a construção do sujeito neoliberal, que dependerá da racionalização do desejo. "Trata-se de governar um ser cuja subjetividade deve estar inteiramente envolvida na atividade que se exige que ele cumpra. Para isso, deve-se reconhecer nele a parte irredutível do desejo que o constitui" (DARDOT \& LAVAL, 2016, p. 327). Nesse ponto, recuamos muito brevemente a um aspecto específico da formação filosófica de Judith Butler, sua tese de doutorado, "Subjects of desire - hegelian reflections in twentieth-century France". Ali, Butler retoma o caráter desestabilizador do desejo como "fonte de deslocamento ontológico do sujeito humano" (BUTLER, 1999, p. 34). Interessa a ela aquilo que o desejo carrega de ambivalente: "Na medida em que desejamos, desejamos de duas maneiras que se excluem mutuamente; ao desejar algo, nos perdemos; ao desejar nosso "eu", perdemos o mundo." Essa experiência de perda de si produzirá, com Butler, uma turbulência na relação até ali estável entre sexo/gênero/desejo, fazendo com que o desejo seja, assim, um elemento de perturbação, nos sujeitos, da coerência entre sexo, gênero e objeto sexual.

O que lemos em Dardot \& Laval, no entanto, é a constatação de que mesmo o desejo, mesmo esse elemento que sustentaria a possibilidade de constituição de sujeitos se confrontarem com a racionalização e disciplinarização das formas de vida, mesmo o desejo havia sido capturado pela racionalidade neoliberal. 'As novas técnicas de 'empresa pessoal' chegam ao cúmulo da alienação ao pretender suprimir qualquer sentimento de alienação: obedecer ao próprio desejo ou ao Outro que fala em voz baixa dentro de nós dá no mesmo (DARDOT \& LAVAL, 2016, p. 327)". Se, como pensam Dardot e Laval, os trabalhadores passam a ser responsáveis pela sua eficácia, passam a intensificar seu esforço de realização que, embora impulsionada pela racionalidade neoliberal, é experimentada "como se essa conduta viesse dele próprio, como se esta lhe fosse comandada de dentro por uma ordem imperiosa de seu próprio desejo, à qual ele não pode resistir (DARDOT \& LAVAL, 
2016, p. 327)". Arriscaríamos mesmo a dizer que essa "ordem imperiosa" dependerá da estabilização do desejo em direções muito bem definidas, demarcadas, delimitadas, controladas, disciplinadas, colonizadas.

Modalizado e normatizado, o desejo torna-se assim uma espécie de último campo de batalha, reduto final de disputa do sujeito. É nesse ponto que acreditamos na necessidade do encontro entre teoria crítica e pós-estruturalismo, a partir da percepção de que, por um lado, o sujeito neoliberal está dominado nos modos de produção de subjetividade, e por outro lado, a precarização das condições materiais traz impactos profundos na vida social. Os "debates feministas" aportariam à filosofia a possibilidade de repensar a categoria sujeito em outros termos que não apenas o da aniquilação, falsa acusação ao pós-estruturalismo, versus recuperação, falácia sustentada na nostalgia de um sujeito universal abstrato, cuja presença a si seria o fundamento da razão e da universalidade; apagamento da emergência dos novos sujeitos de direitos, cuja existência insiste em reivindicar legilibilidade e reconhecimento.

\section{Considerações finais}

Gostaríamos de concluir reforçando o motivo principal que anima esse artigo, a afirmação da atualidade da aliança entre os feminismos de matriz pós-estruturalista e os de matriz materialista, proposta por Fraser nos anos 1990 e em realização nisso que Butler chama de "política das ruas". Para sustentar essa argumentação, traremos algumas considerações sobre o livro Corpos em aliança e a política das ruas: notas sobre uma teoria da performatividade da assembleia, livro em que Butler retoma a questão das alianças. Numa investigação acerca do que, nas inúmeras manifestações que tomaram as ruas desde o Ocuppy Wall Street - passando pela ocupação das praças na chamada Primavera Árabe e pelas Jornadas de Junho, no Brasil, mas também por movimentos como Black Live Matters, Ni una a menos e Mães de Maio -, a análise de Butler une a performatividade linguística com a performatividade corporal, que é interpretada por ela como estratégia de enfrentamento das 
políticas de precarização. Tais políticas não podem ser pensadas sem a dimensão do sofrimento psíquico, de modo que as reflexões de Butler reúnem a materialidade dos corpos com a vida psíquica do poder, a luta por condições materiais com o confronto às formas de sujeição:

Quanto mais alguém está de acordo com a exigência da "responsabilidade" de se tornar autossuficiente, mais socialmente isolado se torna e mais precário se sente; e quanto mais estruturas sociais de apoio deixam de existir por razões "econômicas", mais isolado esse indivíduo se percebe em sua sensação de ansiedade acentuada e "fracasso moral". (BUTLER, 2018b, p. 21)

Acreditamos poder interpretar essa e outras passagens como indicação de que as duas chaves teóricas - pós-estruturalismo e teoria crítica - estão em funcionamento, o que nos permitiria mobilizar a ideia de precariado, que não é apenas um substituto do proletariado, mas o seu necessário deslocamento. Trata-se de pensar a condição humana marcada pela interseccionalidade que modula como cada corpo, cada sujeito, cada sujeita que está experimentando, na sua condição de precariedade, a distribuição de injustiça social, econômica, racial. Dito de outro modo, o debate sobre quem é, afinal, o sujeito do feminismo, tal qual proposto por Butler há 30 anos, se mostra aqui produtivo não apenas para as feministas, não importa de que corrente, mas para o enfrentamento de outra questão, a emergência dos movimentos identitários. A ideia de que essas lutas teriam substituído a luta de classes no momento do seu esgotamento, mas que as reivindicações identitárias seriam insuficientes para operar a crítica ao capitalismo e que estaria, portanto, na hora de voltar à luta de classes, é uma hipótese que esbarra em pelo menos dois problemas.

O primeiro problema, mais ou menos de fácil diagnóstico, é o fim da classe trabalhadora tal qual a conhecíamos na fase industrial do capitalismo, o que faz com que o campo do trabalho perca hegemonia na arena da disputa política. O segundo problema é a necessidade de admitir que a emergência de novos sujeitos políticos aponta para o limite da universalidade - o proletariado ou mesmo sua atualização, o precariado -, cujo questionamento tem sido impulsionado pelos movimentos 
identitários. A apontada aliança feminista, articulando a crítica do materialismo às condições de precarização da vida com a crítica pós-estruturalista, indicando a alocação diferencial dessa precarização em alguns sujeitos e não em outros, é uma aposta de que essa aliança se torne, assim, um operador que pode fazer funcionar a crítica ao capitalismo no seu estágio atual. Talvez seja preciso refazer a pergunta de Mark Fisher (2009) "não há alternativa?" para, ao tentar respondê-la, encontrar um ponto de partida para a invenção de novos sujeitos de desejo. 


\section{Referências:}

Benhabib, Seyla. Feminismo e pós-modernismo: uma aliança complicada. IN: Benhabib, Butler, Cornell e Fraser. Debates feministas um intercâmbio filosófico. Tradução Fernanda Veríssimo. São Paulo: Unesp, 2018.

Butler, Judith. Entrevista para a revista Margem Esquerda. Margem Esquerda, n. 33. Boitempo Editorial: São Paulo, 2019.

Butler, Judith. Fundações contingentes: feminismo e a questão do 'pós-modernismo'. IN: Benhabib, Butler, Cornell e Fraser. Debates feministas - um intercâmbio filosófico. Tradução Fernanda Veríssimo. São Paulo : Unesp, 2018a.

Butler, Judith. Corpos em aliança e a política das ruas. Tradução Fernanda Siqueira Miguens. Rio de Janeiro: Record, 2018b.

Butler, Judith., \& Bretas, A. (2017). Meramente cultural. Idéias, 7(2), 227-248. [BUTLER, J. Merely Cultural. Social Text, vol. 15, n. 3-4, p. 265-277, 1997.]

Butler, Judith. Quadros de guerra - quando a vida é passível de luto? Tradução Sérgio Lamarão e Arnaldo Cunha. Rio de Janeiro: Record, 2015a.

Butler, Judith. Relatar a si mesmo - crítica da violência ética. Tradução Rogério Bettoni. Belo Horizonte: Editora Autêntica, 2015b.

Butler, Judith. Problemas de gênero - feminismo e subversão da identidade. Tradução Renato Aguiar. Rio de Janeiro: Record, 2003.

Butler, Judith. Subjects of Desire - hegelian reflections in twentieth-century France. Columbia University Press, 2a. Edição, 1999.

Butler, Judith. The Psychic Life of Power: Theories in Subjection. Stanford University Press, 1997a.

Butler, Judith. Excitable Speech: A Politics of the Performative. Nova York: Routledge, 1997b.

Butler, Judith. Bodies that matter. On the Discursive Limits of "Sex". Nova York: Routledge, 1993.

Butler, Judith. Gender trouble: feminism and the subversion of identity. Nova York: Routledge,1990.

Cadava, E. Connor, P. Nancy, J.L. Who comes after the subject?, New York, Routledge, 1991.

DARDOT, Pierre \& LAVAL, Christian. A nova razão do mundo - ensaio sobre a sociedade neoliberal. Tradução Mariana Echalar. São Paulo: Boitempo Editorial, 2016.

Davis, Angela. Women, race and class. Nova York, Vintage Books, 1981. [DAVIS, Angela. Mulheres, raça e classe. Tradução Heci Regina Candiani, São Paulo: Boitempo Editorial, 2016.] 
Duménil, Gérard e Lévy, Dominique. A crise do neoliberalismo. Tradução Paulo Cezar Castanheira. São Paulo, Boitempo Editorial, 2014.

DUQUE-ESTRADA, Paulo Cesar. Derrida e a crítica heideggeriana do humanismo. In: NASCIMENTO, Evando (Org.). Jacques Derrida: pensar a desconstrução. São Paulo: Estação Liberdade, 2005.

Crenshaw, Kimberlé W. Demarginalizing the intersection of race and sex; a black feminist critique of discrimination doctrine, feminist theory and antiracist politics. University of Chicago Legal Forum, 1989, pp. 139-167

Derrida, Jacques. A Escritura e a Diferença. Tradução Maria Beatriz Marques Nizza da Silva. São Paulo: Ed. Perspectiva, 2009.

Derrida, Jacques. Gramatologia. Tradução Miriam Chnaidermann e Renato Janine Ribeiro. São Paulo: Ed. Perspectiva, 2013.

Derrida, Jacques. Posições. Tradução Tomaz Tadeu da Silva. Belo Horizonte: Autêntica, 2001

Derrida, Jacques. "É preciso comer bem" ou o cálculo do sujeito. Tradução Denise Dardeau e Carla Rodrigues. Revista Latino-americana do Colégio Internacional de Filosofia. N. 3, 2018.

FISHER, Mark. Capitalist Realism: Is there no alternative? Washington: Zero Books, 2009.

Fraser, Nancy. Falsas antítses: uma resposta a Seyla Benhabib e Judith Butler. IN: Benhabib, Butler, Cornell e Fraser. Debates feministas um intercâmbio filosófico. Tradução Fernanda Veríssimo. São Paulo: Unesp, 2018.

FRASER, Nancy. O feminismo, o capitalismo e a astúcia da história. Tradução Anselmo da Costa Filho e Sávio Cavalcante. Mediações, Londrina, v. 14, n. 2, p. 11-33, jul./dez. 2009. ["Feminism, capitalism and the cunning of history". New Left Review, n. 56, março-abril de 2009]

GONZALEZ, Lélia. A categoria político-cultural de amefricanidade. Revista Tempo Brasileiro, Rio de Janeiro, n. 92-93, 1988, p. 69-82.

GONZALEZ, Lélia. A mulher negra na sociedade brasileira: uma abordagem político-econômica. In: RODRIGUES, Carla; RAMOS, Tânia; BORGES, Luciana (Org.). Problemas de Gênero. Rio de Janeiro: Funarte. (Coleção Ensaios brasileiros contemporâneos), 2017.

Guibert-Sledziewski \& Vieillard-Baron (orgs.). Penser le sujet aujourd'hui. Paris: Méridiens Klincksiek, 1988.

LUGONES, Maria. Colonialidad y género. Tábula Rasa. Bogotá, Colômbia N. 9, 2008, pp. 73-101.

LYOTARD, Jean François. A condição pós-moderna. 6.ed. José Olympio Editora: Rio de Janeiro, 2000. 
MANIGLIER, Patrice. Térontologie saussurienne: ce que Derrida n'a pas lu dans le Cours de linguistique générale. IN: MANIGLIER, Patrice (org.) Le moment philosophique des années 1960 en France. Paris: PUF, 2011.

RODRIGUES, Carla. O sonho dos incalculáveis: coreografias do feminino e do feminismo a partir de Jacques Derrida. Dissertação de mestrado, Filosofia, PUC-Rio, 2008.

RODRIGUES, Carla. Coreografias do feminino. Florianópolis: Editora Mulheres, 2009.

RILEY, Denise. "Am I that name?" Feminism and the Category of "Women" in History. Basingstoke, UK: Macmillan, 1988.

SAFATLE, Vladimir. Fazer justiça a Freud: a psicanálise na antessala da Gramatologia. IN: HADDOÇK-LOBO, R. et ali (org). Heranças de Derrida - da linguagem à estética. Volume 2. Tradução Ana Luiza Fay. Rio de Janeiro: NAU Editora, 2014.

QUIJANO, Aníbal. Colonialidad del poder, eurocentrismo y América Latina. IN: QUIJANO, Aníbal; CLÍMACO, Danilo Assis. Cuestiones y horizontes: de la dependência histórico-estructural a la colonialidad/descolonialidad del poder. Ciudad Autónoma de Buenos Aires: CLACSO.

WAJCMAN, Gérard. A arte, a psicanálise, o século. IN: Lacan, o escrito, a imagem. Tradução de Yolanda Vilela. Belo Horizonte: Autêntica, 2012. 